\title{
An alleged case of unusual human bite
}

\author{
Rathnaweera RHAI ${ }^{\mathbf{1}}$, Vidanapathirana $\mathbf{M}^{\mathbf{2}}$ \\ Lecturer ${ }^{1}$, Senior Lecturer ${ }^{2}$, Department of Forensic Medicine, Faculty of Medicine, University of \\ Ruhuna, Karapitiya, Galle
}

\section{History}

A 33-year old man while walking along a deserted road in "Urawela" on $18^{\text {th }}$ June 2008 around 5.00 p.m. had an argument with one of his neighbors he met. That person had been drunk at that time. Su $\square$ nly the neighbor had grabbed the victims head and bitten the face. Then he ran away. The victim was then admitted to Base Hospital Balapitiya and from there he was transferred to Teaching Hospital, Karapitiya. Later, the assailant denied all charges. There were no eye witnesses to prove the case as well.

\section{Medico-legal examination}

Roughly a semicircular tissue loss of $3 \times 4 \mathrm{~cm}$ was found under the left eye with irregular margins. No other injury was present.

\section{Discussion}

Human bites are relatively common, especially in cases of child abuse and in adult sexual assault. In the former, bites may be anywhere on the child's body, favorite sites being the arms, hands, shoulders, cheeks, buttocks and trunk.
In cases of sexual abuse, bites may be sexually oriented or be distributed on any part of the body. Common sites are breast and nipple, neck, shoulders, thighs, abdomen, pubis and even vulva ${ }^{1}$. Some bites are self-inflicted; falls on the face or a fit may cause the tongue and lips to be badly bitten. Some persons deliberately bite themselves to fabricate injuries for a variety of reasons ranging from personal gain to psychiatric disorders. Multiple bite marks which are seen on accessible areas such as arms raise the suspicion of self-infliction, especially in older children and teenage girls ${ }^{1}$. Bite marks can also be seen in victims of interpersonal violence.

Teeth marks may be abrasions, bruises or lacerations or a combination there of. If the bite is old, then healing process will leave progressively less detail. In a forcible bite, extensive subcutaneous bruising may spread laterally and blur the outline. Where teeth have been forcibly applied, the typical appearance is of two 'bows' with their concavities facing each others and a gap at each end. Within this may sometimes be suction petechiae which are often present without teeth marks in the so called 'love bites' . 


\section{Investigation of a bite mark}

Bite mark comparisons are accepted in court as roughly equivalent to finger prints. If a forensic odontologist is available, he should conduct the examination ${ }^{2}$.

First, the bite mark should be carefully photographed. Photographs should be taken from different angles, including a direct perpendicular view point, with the plane of the film at right angles to that of the lesion with a scale $^{2}$.

Swabs of the bite should be taken to recover saliva. This can sometimes be important in helping to identify or exclude the assailant, if he or she is one of $80 \%$ of people who are 'secretors' that is, individuals who excrete their blood group substances in their saliva.

Then if facilities are available, an impression of the bite should be made. This consists of laying a plastic substance over the bite mark, which then hardens, providing a permanent negative cast of the lesion. A forensic odontologist could match the assailant with the cast ${ }^{1}$.

\section{Problems}

1. Absence of an eye witnesses, refusal of charges by the assailant and an unusual nature of the bite made it our duty to prove the cause of injury as a human bite. Presence of only the lower arch of the bite and the upper arch been removed with the tissue including lower eye lid, made the appearance of the bite unusual.

2. Lack of a Forensic Odontologist in Southern Province to compare the bite and the assailant for identification. Furthermore, the production of a cast on this bite was difficult due to the raw base of the injury and close proximity to the eye.
3. Immediately after this incident, patient had washed his wound so that the collection of swabs from wound for saliva was of no value.

Victim was referred to the consultant dental surgeon, Teaching Hospital Karapitiya, who confirmed the injury as a human bite. Victim was then referred to the Forensic Odontologist in Colombo to prepare a dental casting. Once the results are available, we will be able to match the casting with the assailants' dentition enabling us to prove or disprove the allegation.

Unlike other bites, due to considerable loss of facial tissue, this type of injury can also amount to a grievous hurt due to permanent facial disfiguration under limb ' $\mathrm{f}$ ' of section 311 of the penal cord.

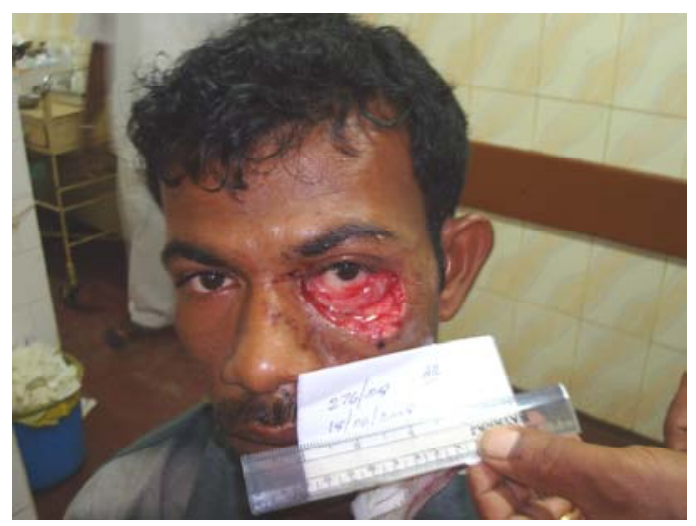

Figure 1 - The unusual bite mark

\section{References}

1. Knight B, Saukko P, Knight's Forensic Pathology, $3^{\text {rd }}$ edition, Edward Arnold, Oxford, 2004: 527-32.

2. Di Maio VJM. Dana ES, Hand book of Forensic Pathology, $1^{\text {st }}$ edition, Texas, Lande Bioscience, 1999: 15-6. 